Article

\title{
Understanding Emerging Media: Voice, Agency, and Precarity in the Post-2011 Arab Mediasphere
}

\author{
Yazan Badran ${ }^{1,2}$ \\ ${ }^{1}$ Echo, Vrije Universiteit Brussel, Belgium; E-Mail: yazan.badran@vub.be \\ 2 imec-SMIT, Vrije Universiteit Brussel, Belgium
}

Submitted: 3 May 2021 | Accepted: 26 July 2021 | Published: 17 December 2021

\begin{abstract}
The decade following the 2010-2011 Arab uprisings saw a flourishing of emerging media organisations across the region. The most recognisable examples of these new independent media actors include Enab Baladi in Syria, Mada Masr in Egypt, and Inkyfada in Tunisia. However, this phenomenon comprises a much more diverse set of actors from small-scale associative radio stations in Tunisia to numerous exilic Syrian media outlets. Building on previous research as well as recent fieldwork in Tunisia and Turkey, this article is an attempt to make sense of the genesis, development, and relevance of this new class of media actors. We argue that these emerging media organisations can be seen to represent specific interventions into the politics of voice in their various national and local contexts, but ones that share similar logics. To elucidate this argument, we propose a multi-dimensional understanding of these interventions that brings together voices (actors, issues, discourses), modalities of voice (organisational models, values, production value), and the underlying political economy of these emerging media (funding, institutionalisation). However, the article also argues that these interventions, and the logics they share, themselves belie a complex interaction between the political and professional agency and precarity of these media organisations and the individuals, and groups, behind them. We believe that combining these two perspectives is a necessary step for a more nuanced understanding of the nature and practice of these emerging media organisations.
\end{abstract}

\section{Keywords}

Arab uprisings; emerging media; institutionalisation; media development; MENA; politics of voice; professionalisation

\section{Issue}

This article is part of the issue "Ten Years after the Arab Uprisings: Beyond Media and Liberation," edited by Hanan Badr (Gulf University for Science and Technology, Kuwait) and Lena-Maria Möller (Max Planck Institute for Comparative and International Private Law, Germany).

(C) 2021 by the author; licensee Cogitatio (Lisbon, Portugal). This article is licensed under a Creative Commons Attribution 4.0 International License (CC BY).

\section{Introduction}

The decade following the 2010-2011 uprisings in the Middle East and North Africa (MENA) saw a flourishing of emerging media organisations across the region. The most recognisable examples of these new independent media actors include now-established outlets such as Enab Baladi in Syria, Mada Masr in Egypt, and Inkyfada in Tunisia. This phenomenon, however, comprises a much broader class of actors across the region. These actors vary widely in size, reach, style, and medium; from small-scale local associative radio stations in Tunisia to the numerous exilic Syrian media outlets. To a significant extent, the emergence and development of these media actors is a response to particular dislocations, opportunities, and crises of mediation following the uprisings in their own (often national) contexts. While acknowledging this, this article is an attempt to zoom out of the local scale to make sense of the broader and shared logics underlying this decade of emerging media.

The argument presented herewith builds on the author's previous research into emerging media, including recent on-site fieldwork in Tunisia-focusing on associative radios-and Turkey-focusing on exilic Syrian media. The fieldwork across Tunisia combined field visits to 11 local associative media organisations and 20 semi-structured interviews with editors and journalists of these media, as well as representatives from 
institutional actors involved in the field of associative media (see Badran et al., 2021). The fieldwork in Turkey entailed three months of participant observation at the newsroom of Enab Baladi, a Syrian exilic media outlet based in Istanbul, as well as 18 semi-structured interviews with journalists and editors (see Badran \& Smets, 2021). Finally, the insights from these two studies were complemented by in-depth interviews with editors from emerging media in Egypt (Mada Masr) and Jordan (7iber; pronounced "Hiber").

The media organisations featured in this study encompass a range of political contexts, mediums, and organisational models. The insights gained from this diverse field are used in this article to reflect on the entanglement with voice that these emerging actors collectively represent; to propose a tentative framework that can be used to analyse this entanglement. The article also aims to historicise these different projects and contexts of emerging media by placing them in conversation with one another, and with developments and changes in the journalistic field more broadly. The framework we propose to make sense of emerging media centres the notion of voice as a possible entryway to conceptualising their genesis and development, and a perspective through which we can provide a more complex analysis of their practices and trajectories.

\section{Voice and Its Politics}

The question of voice is at the heart of the emergence and development of these organisations as well as that shared generative political moment of 2011 and its aftermath-which for some represented an absolute point of genesis, e.g., Enab Baladi, while for others one of important inflexion and re-constitution, e.g., 7iber. Across the region, polities that, at least partly, built their stability upon an acute denial of voice (see, for example, Badr, 2021, on Egypt; Cavatorta \& Haugbølle, 2012, on Tunisia; Wedeen, 1999, on Syria;), and a constant (and in human terms, brutal) management of the conditions of "muteness and ventriloquism" (Watts, 2001), were unequivocally repudiated by the crowds amassed in Tunis, Cairo, Homs, and Manama, to mention but a few. Their rebuke was an undeniable act of voice that demanded and compelled a response.

Voice here, at a most basic level, should be understood as both the process (and ability) of engaging in self and collective narratives of one's life as well as the conscious valuing and privileging of such process (Couldry, 2010). In Couldry's (2010) account, voice is a form of "reflexive agency" that is grounded in (public) relations of sharing and exchange in the social world and one that is dependent on material and narrative resources for its efficacy. Indeed, as Manyozo (2016, p. 57) notes, voice is not a product that "can be packaged" as such, but a communicative act, "a form of lived reality, a critical actuality, a conversational and dialogical pathway through which the oppressed question their socio-political and economic reality." Voice's transformative potential-and indeed its ability to function as a (communicative) proxy for political and moral agency-lies in that dialectics of exchange where individuals and groups learn of themselves and others (Couldry, 2010; Manyozo, 2016).

As a reflexive agency, voice is also a quintessentially ethical proposition in that it centres "the problems and obligations incumbent in community building and arouses in persons and groups the frustrations, sufferings, and joys of such commitments" (Watts, 2001, p. 185). This nuance is important if we are to delineate an engagement with voice that goes beyond a unilinear account of voice (as an expression) and integrates the questions of recognition and listening (Couldry, 2009; Dreher, 2009; Schmoll, 2021). Couldry's bifurcated approach to voice (as both a process and a second-order value) opens the door for establishing a more ecumenical framework of voice, which is at least as concerned with how voice is recognised and made effective, as it is with the practice and ethics of speaking up.

Analytically, centring the engagement with voice in our understanding of emerging media is an attempt to refract the (academic) gaze to peer through the perspectives of these actors, and in so doing, interrupt some of the dominant perspectives on the role and nature of mediation in the 2010-2011 Arab uprisings and their aftermath. In this, we follow in the footsteps of Hirschman (1970), Watts (2001), Couldry (2010), and others who explicitly engage with voice as a way to displace and interrupt certain dominant rationalities (the economic rationality of "exit" in Hirschman's classic account, 1970, or neoliberal rationality in the case of Couldry, 2010).

In our case, centring the notion of voice in our account propels us to interpret and evaluate the discourses, practices and structures of these actors as (contingent) frameworks for the selection, amplification, and privileging of certain voices and the modalities to make these voices more effective. On one level, it allows us to interrupt the technocentric analysis of these actors. Such accounts of the Arab uprisings and their aftermath (e.g., Howard \& Hussain, 2013) tend to subsume the different (and messy) processes of voice-where the dialectics of exchange, for example, become subsumed into the abstract notion of "circulation" (see Dean, 2010)into a reified sense of technology which becomes the central articulation and the way we make sense of the agency of these actors.

On another, it allows us to complicate and challenge functionalist approaches that privilege a hegemonic (and often linear) model of democratisation (famously critiqued by Carothers, 2002) as the lens through which to understand the role played by these actors. In these accounts, often dominant in technocratic policy prescriptions and development programmes (see, for example, Norris, 2008), the media's role is circumscribed to that of the guarantor of "good governance" and "democratic transition." But as Teti and Gervasio (2021) show in the 
case of Egypt, the EU's broader discourse on democracy promotion in the region has also tended to "delegitimise both the conception of democracy" held by the indigenous populations, as well as their concrete "political and socioeconomic demands" (p. 1), thus completely obfuscating the question of voice in the process.

A shift in the perspective towards voice means centring, above all else, the actual processes of exchange of narratives, their underlying modalities and resources, and the changes, evolutions, and contestations in these processes, as well as how we make sense of the agency of these actors.

\section{Emerging Media as an Intervention}

In the following sections, we elucidate a different understanding of emerging media as representing specific interventions into the politics of voice in their various national and local contexts, but which nonetheless share similar logics. We propose a multi-dimensional understanding of these interventions that brings together voices (actors, issues, discourses), modalities of voice (organisational models, norms, production value), and the underlying political economy of these emerging media (funding, institutionalisation).

\subsection{Voices}

Perhaps the most recognisable and intuitive dimension of the intervention constituted by emerging media organisations is the range of voices, discourses, and actors they channel into the public sphere. The heterogeneity and diversity of these voices are, if anything, a testament to (and a function of) how deeply controlled and sanitised some of these media landscapes were before the 2010-2011 uprisings (Cavatorta \& Haugbølle, 2012; Wedeen, 1999). Indeed, as Wessels notes in her study of Syria's video-activist collectives, these actors represented a movement from a politics of simulacrum-of "As If" (Wedeen, 1999) - to an attempt to document "life and politics 'As It Is,' in a realistic cinema of facts" (Wessels, 2017, p. 169).

The overwhelming majority of the founders of these media outlets, as well as the journalists that make up their ranks, were not socialised in the mainstream media sector of their countries (whether state media, large private media or pan-Arab media). Indeed, many of them actually transitioned into journalism by way of their activism before or during the protests, or in response to the opportunities that opened up shortly in their aftermaths, often developing their journalistic skills in concert with the maturing of their respective media outlets. Even notable exceptions such as Lina Attallah, founder of Mada Masr, or Lina Ejeilat, co-founder of 7iber, who were established journalists before 2011 (working for Egypt Independent and Reuters, respectively), were far more well-known to English-speaking audiences. Examples of these new actors abound across the region, whether in Tunisia (Badran et al., 2021; Mezghanni, 2014), Libya (Wollenberg \& Pack, 2013; Wollenberg \& Richter, 2020), Syria (Issa, 2016; Wall \& el Zahed, 2015) or beyond.

What makes this an important intervention into the politics of voice in the region is not simply the influx of new actors alone, but how this voice is "translated" at the level of representation and the cacophony of new discourses and debates these actors bring with them. The rise of Kurdish-language journalism in Syria post-2011, after nearly a half-century of a statesanctioned policy of linguicide (Hassanpour et al., 2012), is emblematic in this regard (Badran \& De Angelis, 2016). So is the rise of associative media in Tunisia and its deep articulation with issues of regional marginalisation and inequality in the country (Badran et al., 2021).

These emerging media actors became important vehicles for in-depth critical reporting in contexts where state and private media are largely co-opted by the regime. Mada Masr's in-depth reporting on the military establishment's entanglement within, and capture of, different economic sectors in Egypt under President Abdelfattah el-Sisi became an important resource for researchers and the public alike, despite the incessant harassment of the regime (Badr, 2020). Similarly, 7iber's coverage of the 2014 Israeli-Jordanian gas deal (for the archive see "What we know about," 2016) and the intricacies of the special agreement on border delineation between the two states (see, for example, Jarrar, 2018), helped galvanise a popular movement in the country in opposition to these deals (Ryan, 2018).

The expansion and pluralisation of voices facilitated by emerging media organisations is also visible in their openness to covering and hosting conversations on several political and social taboos that had hitherto been absent, or heavily sanitised and instrumentalised, in traditional media coverage-including, but not limited to, sectarianism and sectarian belonging (Badran \& Smets, 2018), gender (Chancellor, 2020; Charaf, 2014), LGBTQ politics (Saleh, 2020; Sbouai, 2015), and sexual violence (Zaki, 2021). Just as important is their responsiveness to more prosaic, but no less pressing, concerns such as in Enab Baladi's in-depth coverage of property rights and housing for displaced people (for the archive, see Enab Baladi, n.d.), or the centring of the quotidian in the critique of regional inequality in Tunisian associative media (Badran et al., 2021).

\subsection{Modalities}

The second dimension on which we can observe a shared logic among these emerging media actors is an explicit orientation towards the professionalisation of journalistic work. Much of the early accounts of the mediatised dimension of the 2010-2011 Arab uprisings, and their aftermaths, centred on and emphasised the role and impact of "citizen journalists" and "media activists," in particular how their user-generated content spread over social media and/or was integrated into mainstream 
media coverage. This approach built on existing scholarly interest triggered by the blogging wave that spread across the region in the 2000s (el-Nawawy \& Khamis, 2013; Radsch, 2008; York, 2012).

The amalgamation of networked protests and media activism, during and immediately following the Arab uprisings, was largely seen through the lens of Castells's "mass self-communication" (Castells, 2009), privileging a mode of communication that is "'self-generated,' 'self-directed' and even 'self-selected' in its reception" (Wall \& el Zahed, 2015, p. 722). Such an approach to communication emphasised the movement away from "professional" production towards a celebrated "amateur" aesthetic (Russell, 2016), away from hierarchical structures and organisations towards networked individualism. Key to this is also the supposed empowering effect these shifts have in terms of civic engagement and democratisation (el-Nawawy \& Khamis, 2013; Shirky, 2009).

Emerging media organisations, we argue, show a movement in the opposite direction. Broadly speaking, from a celebration of the amateur to an emphasis on professionalisation, and consequently, away from the centring of individual contributors towards more elaborate organisational and institutional structures. The transition of 7iber from an open platform of citizen journalism to a full-fledged media organisation focused on in-depth reporting is indicative of this shift. As co-founder Lina Ejeilat reflected:

We started feeling that if this project is to grow, we need to be dedicated full-time..... Opinions are important, and having spaces for opinion is important, but what is genuinely missing and needed is in-depth journalism that contributes to knowledge production. This was our approach from mid-2012. We left our other jobs, and we became engaged in the project full-time. (Personal communication, 2019)

This transition in the Syrian context was even more dramatic and pronounced. User-generated content disseminated by activists and citizen journalists in the early months of the uprising were instrumental in communicating its developments and showcasing the brutal and repressive tactics of the Syrian regime, especially in the context of a blanket ban on foreign reporters (Andén-Papadopoulos \& Pantti, 2013; Salama, 2012). Nevertheless, this celebrated horizontality and openness also created conditions of fragmentation, political manipulation, and epistemic insecurity as the sheer volume of content shared was impossible to verify, contextualise, and curate (Al-Ghazzi, 2017; De Angelis, 2011; Della Ratta, 2018; Wedeen, 2019). The emergence and proliferation of media outlets and platforms that emphasised and re-centred editorial processes (e.g., verification and selection) and structures is arguably a response to these outcomes, and an attempt to reclaim the power of narrative, of voice, that seemed to dissipate amid an atmosphere of "permanent digital suspicion" (Della Ratta, 2018, p. 121).

Professionalisation in this sense, we would argue, is seen in the orientation towards more centralised organisational structures and editorial processes, a critical engagement with journalistic norms, and a focus on craft and higher production value. Organisationally, we witness a pronounced movement towards formally and publicly constituting the organisation as a registered (non-profit, in most cases and where it is possible) entity (Badran, 2020; Badran et al., 2021). This is accompanied by a growing emphasis on editorial oversight and an elaboration of editorial policies and processes-e.g., with regards to sourcing, language/vocabulary, gender, etc. (see Brownlee, 2020, pp. 178-182; Tatomir et al., 2020).

These developments on the editorial level are constructed through an explicit engagement with and adaptation of mainstream journalistic norms and vocabulary. The diversity of contexts and types of media necessarily means that the way these norms are understood and operationalised in-situ differs accordingly. In a local associative radio station in Tunisia, objectivity is understood in terms of transparency, integrity, and lack of political bias (for example in national or local election coverage), while sometimes acknowledging that it has limited purchase when it comes to advocating for the region's development. In the newsroom of Enab Baladi, however, objectivity-understood in terms of balance and the inclusion of multiple points of view, but also differentiated from "neutrality" - is seen as an essential component of the journalist's professional identity and practice.

Nevertheless, whether in the local associative radios in Tunisia's marginalised towns or in Enab Baladi's elaborate newsroom in Istanbul, the workers in these media outlets make their claims to authority first and foremost in their capacity as "professional journalists" rather than as citizens or activists. Mada Masr's editor-in-chief, Lina Attallah, in reflecting on this says that she saw their role as "restoring the very classical role of journalism as an act of bearing witness, of witnessing and telling what you've just seen" in a polarised environment that had become increasingly dominated by the regime's media machine (Hafez, 2015). The irony, however, as expressed by 7iber's Lina Ejeilat, is that "professional journalism" in contexts of authoritarianism becomes itself a form of activism:

In practice, what is journalism?....You go down and you examine, and you become a witness to what is happening. But bearing witness in countries and societies that want to hide information, want to hide the truth, and disfigure the narratives is also an act of activism. (Personal communication, 2019)

The development and refinement of journalistic craft and output are seen as important aspects of this process of professionalisation-and in claiming authority on that basis-in emerging media. For example, in Mada Masr, 
the basic competence of professional newsgathering was seen as key:

We thought we needed to do newsgathering-this operation that is monopolised by large organisations with big newsrooms, or the big TV stations with live studios and equipment, it should not stop there, because there was horrific distortion at this very level of information. We felt that before analysis, opinion, reflection, and unpacking, we needed to provide the information itself. (Personal communication, 2019)

While Enab Baladi's training programme for aspiring journalists places emphasis not only on the quality and clarity of writing, and respect for established journalistic norms, it is also underpinned by a rigorous deference to classical journalistic forms and content genres (news items, reports, human interest stories, etc.).

The intervention that emerging media organisations articulate in terms of the modalities of voice-making entails a diverse and heterogeneous array of concrete practices that correspond to the diversity of actors and contexts. But the underlying logic of these practices is an orientation towards the "professionalisation" of journalistic work at different levels, and the valorisation of those practices, values, and organisational models seen to embody this process of professionalisation.

\subsection{Political Economy}

The third dimension lies in shifts at a structural political-economic level that accompanied and were coconstituted by emerging media organisations. These shifts are seen in the new economic opportunity structure that underlies this new class of actors, as well as in the new institutional arrangements and practices they experiment with.

Economically, the MENA uprisings and the collapse in statist logics and control, to varying degrees, opened the door to new modalities of sustaining and funding nascent media organisations (see, for example, Sakr, 2016). The most prominent and consequential of these support mechanisms has been direct (financial and professional) support from media development actors (El-Issawi \& Benequista, 2020; Tatomir et al., 2020). Media development flows into the MENA region increased from 18,7 million USD in 2010 to 106,7 million USD in 2019, an increase of nearly $600 \%$ (based on OECD official development assistance data, see Badran, in press).

Due to the contexts in which these media organisations operate, attaining financial self-sufficiency is an extremely arduous task. By and large, this is due to political pressure that forecloses the possibility for autonomous commercial operations for independent media (see Sakr, 2016). But even in contexts where such political pressure is attenuated (as in the case of Tunisian associative media), worsening economic conditions across the region post-2011 has meant that such funding streams are extremely narrow (Badran et al., 2021).

Thus, media development aid, whether through direct grants and project funding, equipment and material, or workshops and training, functions as an essential lifeline for emerging media organisations. Moreover, in a region where investments in media are often confined to state actors and associates favoured by a system of nepotism (e.g., Della Ratta et al., 2015), and thus seen as largely corrupting, this alternative model of funding lends credibility to emerging actors as independent media makers.

The integration of media development aid into this field of media actors is deeply interlinked with the other shifts described herewith. The ability of such media actors to professionalise their operationsprovide full-time employment, develop editorial policies and enforcement, develop elaborate organisational and administrative structures, support content production and skill development-is decidedly dependent on this support and its persistence thus far (see Breiner, 2019).

Seen from a different perspective, these shifts are also deeply shaped and influenced by this support. The workshops and training offered by media development organisations and their interlocutors were a factor in circumscribing the professional identity of these journalists and media makers as they developed their craft (again, in divergent and differentiated ways across contexts and actors). One associative radio journalist in Tunisia, in reflecting on the establishment of the radio and her trajectory there, put this in stark terms:

These training courses helped us understand what it means to be a media worker, how to be a professional, how to deliver the information accurately, not to have bias. We learned what media is. We learned about professional ethics....We became media workers, and we think of what we are producing. (Personal communication, 2019)

On an institutional level, the proliferation of different experimentation with new institutional settings and structures constitutes another important facet of the development of emerging media. The Ethical Charter for Syrian Media, for example, is a collaborative effort by its members-26 Syrian emerging media outlets - to establish a binding media regulation body for the sector (see Sarkisjan, 2021). Other such experiments in (parallel-)institution building include the Syrian Journalist Association (formed as a labour union to represent Syrian journalists who were excluded from the Syrian Journalists Union, controlled by the regime), and the Syrian Female Journalists Network (Tatomir et al., 2020). Similar experimentation on a sectoral level can be seen in Tunisia where different associative media actors cooperated in establishing two institutional bodies to represent them and advocate on their behalf (Badran et al., 2021). 
These institutional arrangements, collaborations, and networks proliferate at different levels. The Syrian Network for Print Media, for example, pooled together resources from several print media to organise a joint print and distribution operation for member organisations (Tatomir et al., 2020). On a regional level, the February Network (see "How do we continue?," 2019) brought together different emerging media organisations from Syria, Lebanon, Jordan, and Egypt to organise and establish a year-long training programme for aspiring journalists under the name Alternative Academy for Arab Journalism (see https://caforarabjournalism.com). On an international level, emerging media organisations have become increasingly integrated into independent and investigative journalism networks such as the Organized Crime and Corruption Reporting Project and Global Investigative Journalism Network.

These different experiments in institutional and coalition building combine a top-down encouragement from media development donors-whose funding makes these initiatives possible-and bottom-up collaboration from emerging media actors. More importantly, however, they reflect a deep awareness among emerging media organisations of their role, and that of other emerging media outlets-both individually and collectively-as representing a unique class of actors within their own contexts and the region.

\section{Voice, Agency, and Precarity}

Thus far, our analysis has mapped out the logics that underlie these interventions into the politics of voice of the region represented by emerging media organisations. However, we should be careful in ascribing a linear directionality or unproblematic inevitability to these interventions. Indeed, they belie a complex network of choices, contestations, and contradictions that reflect the interaction between the political and professional agency and precarity of these media organisations, and the individuals and groups behind them.

Media development funding is in many ways a condition of possibility for the persistence and survival of these actors. However, and perhaps because of that, it also represents a deeply contested and ambiguous terrain with implications on other dimensions (see Brownlee, 2017). Political and institutional logics embedded in such funding programmes (e.g., subordination to foreign policy considerations of donor countries, aid-dependency, short-termism, and choice of indicators) represent significant challenges for their eventual beneficiaries (see Badran, in press; Brownlee, 2017; Noske-Turner, 2014; Waisbord \& Jones, 2010). These challenges, and the choices made in responding to them, have direct and indirect implications for emerging media's engagement with the question of voice. Emerging media organisations, in dealing with the political and economic implications of this funding model, have to manoeuvre themselves in two different directions.
Firstly, they have to manage how this funding might impact their public legitimacy. As one Tunisian journalist reflected, "There is a stigma when you say this project is done in partnership with this or that donor. There is a lot of suspicion. For whose benefit are you working?" (Personal communication, 2019). Beyond matters of perception, there are also ethico-political choices that need to be made as Lina Attallah of Mada Masr makes clear:

There is a limit to what kind of funding we accept. We obviously do not take state funding from the US or the UK for example, which have been directly involved in screwing our people, in very, very direct ways. We prefer to work with more independent media development organisations. (Personal communication, 2019)

Secondly, they have to manage the dependency this funding model creates and the stark power imbalance between them and their international interlocutors. By 2016, the protraction of the Syrian conflict significantly shrunk the amount of media funding available and spurred a collapse and consolidation of the emerging media sphere into a handful of outlets (Badran, 2020). But it also crystallised some successful strategies for managing these contingencies, for example in the case of Enab Baladi, by spreading the risk across different donors and different sections of the organisation, thus attenuating the inherent imbalance of power with international media development organisations-albeit at the cost of growing administrative and bureaucratic complexity (Badran \& Smets, 2021).

These are questions and dilemmas that emerging media actors are acutely aware of and have to navigate daily as this editorial on SyriaUntold makes clear. The authors describe a double-bind between a powerful Western gaze in mainstream media that obscures local narratives (for example in covering the destruction of Palmyra or environmental degradation) and an opposite pressure (operationalised in funding priorities) that might valorise these emerging indigenous voices but only in certain circumscribed spaces and modes of visibilitywhat the authors called the "Palmyra Syndrome":

For non-profit organisations, including SyriaUntold, which mainly relies on NGOs to produce content, it is not easy to find funding to cover certain issues, such as the environment. Sometimes such proposals are turned away with answers such as: "We are not sure Syrians would be interested" or "could you instead give us a proposal on human rights, or more political issues?" (Youssef \& De Angelis, 2021, para. 18)

Thus, grant funding, should not only be seen as liberating emerging media actors from the pressures of market and state in their restrictive environments (an enabling function), but also as presenting them with several dilemmas and challenges in terms of their internal/external legiti- 
macy as well as balancing editorial independence with a condition of aid dependence (restrictive function). Grant funding, in a sense, also distorts the "emerging media market" by artificially privileging certain organisational models over others (e.g., ability to register the organisation in Europe or the US), rewarding actors who are better able (and willing) to respond to changes in donors' preferences and concerns (e.g., through thematic funding channels), as well as rewarding increased investment in administrative functions (e.g., monitoring and reporting, grant writing) as opposed to editorial functions.

The challenges of balancing an array of ethicopolitical and professional choices in the context of a political economy constituted by development aid are not limited to emerging media in the MENA region; analogous examples from Burma/Myanmar (Brooten, 2016), Nigeria (Myers, 2018), and other countries (Cook, 2016a, 2016b) reflect similar dynamics and challenges. More broadly still, the questions faced by these actors on issues from editorial independence, financial viability, and the increased precarisation of journalistic work echo contemporary debates in the field of journalism writ large (Deuze \& Witschge, 2020; Waisbord, 2019; Zelizer, 2015).

Moreover, these dilemmas and challenges are not only exogenous in nature, but they also arise internally in dealing with any number of issues related to representation and participation (see, for example, Matar \& Helmi, 2020; Saleh, 2020). Indeed, as the professionalisation process of these actors proceeds towards the constitution of elaborate organisational and administrative apparatuses, it brings with it a more profound sense of the responsibility to define the type of workplace it constitutes:

What is that curatorial process of putting together an institution that acts as an ecology of care to its team members?.... How do you invest in proper healthcare insurances? How do you organise sabbaticals? How do you deal with burnout? How do you think of wellness and well-being? (Personal communication, 2019)

In Mada Masr's case above, the challenge is thus twofold (though intricately interwoven): dealing with the political precarity associated with journalistic work in an authoritarian context, as well as negotiating economic precarity in neoliberal times. Different contexts and actors have to face up to these same questions, albeit under different guises. Enab Baladi, for example, has to negotiate the different layers of precarious labour and precarious life within a specific condition of displacement and exile (Badran \& Smets, 2021). While associative radios in Tunisia have to engage with questions about the balance of volunteer and remunerated labour in a context of worsening economic conditions (Badran et al., 2021).

The answers to these questions are seldom straightforward in their implications. Enab Baladi, for example, can be seen to protect its editorial and financial independence (e.g., in opting for smaller grants, from diverse sources) by cascading the sense of precarity down to the staff (e.g., in the form of low remuneration), which in turn brings about other unintended consequences (e.g., in the form of high rates of staff turnover and lack of institutional continuity; Badran \& Smets, 2021).

Finally, a similar set of dilemmas emerge in the competition between these media actors themselves for the scarce (and increasingly unpredictable) funding within that closed system, the inequalities this competition creates, and what implications that has on the plurality of voices in this sphere.

These questions, and the experimentation in engaging with them, necessarily straddle both the endogenous and particularistic (geographical and political) contexts of dislocation, as well as exogenous pressures and dislocations in the field of journalism more generally. Delineating and engaging on this level of analysisthe underbelly of the phenomenon of emerging media organisation-is directly related to our understanding of these media in terms of their intervention into the politics of voice and the limitations of that intervention. Taking these considerations into account is necessary to understand the nature, extent, and limits of these interventions. Indeed, it not only allows us to nuance and complicate our account of emerging media organisations but also to de-essentialise and historicise them and to place them in conversation with analogous actors and developments more globally.

\section{Conclusions}

The aftermath of the Arab uprisings presents a highly variegated regional context stretching from fundamental state reform in Tunisia, to state collapse in Syria and authoritarian retrenchment in Egypt. Thus, the particular political, economic, and social contexts in which these media actors emerge and attempt to ply their trade are highly divergent. Nevertheless, this article aimed at making an argument for a broader understanding of post2011 Arab emerging media beyond the particularities of their national and local contexts, by placing them in conversation with one another, and with developments and changes in the journalistic field more broadly. It does so by centring the notion of voice as the lens through which to interpret and evaluate the discourses, practices, and structures of these emerging media actors.

The thesis we propose is that emerging media organisations represent specific (multi-dimensional) interventions into the politics of voice in their various national and local contexts, albeit ones that share similar logics: pluralisation of voice, professionalisation, and relative (economic) independence from market and state. Different contexts necessarily mean that the operationalisation of these logics differs accordingly-e.g., the pluralisation of voices in Syria can be seen in the rise of Kurdish journalism, while in Tunisia, it can be seen in the proliferation of local associative media and their articulation with longstanding regional marginalisation. 
Similarly, at the level of modalities, we see a diverse and heterogeneous array of concrete practices. However, the underlying logic of these practices, we argue, tends towards a valorisation of the "professionalisation" of journalistic work (in terms of structures, values, and craft). The political economy underlying this sphere of emerging media, largely underpinned by grant funding from media development organisations, also shows a shared tendency towards institutionalisation (at different levels). The different experiments by emerging media in building sectoral or regional institutions reflect a deep awareness of themselves (and of each other) as representing a unique class of actors in their own contexts and the region.

Finally, we also show that these interventions, and their underpinning logics, belie a complex dynamic between the political and professional agency and precarity of these media organisations and the individuals and groups behind them. Indeed, far from suggesting a teleological essence to the interventions described above, we emphasise that they are a function of contingent, and sometimes contradictory, external and internal pressures, whilst also representing the unique and context-specific responses of emerging media actors themselves to such pressures. Seen through a critical framework of voice, this dynamic illustrates both the limits and robustness of these interventions. More broadly, to paraphrase Watts (2001, p. 185), it also evokes the problems and obligations incumbent in an engagement with the politics of voice, as well as the frustrations, sufferings, and joy of such commitments.

\section{Acknowledgments}

I would like to express my immense gratitude to the journalists, editors, and media outlets interviewed and investigated in the course of this research. I would also like to thank my academic hosts for the fieldwork in Tunisia (Centre d'Etudes Maghrébines à Tunis) and Turkey (Kadir Has University, Istanbul). My gratitude to the editors of this thematic issue, and the anonymous reviewers, for their constructive and detailed comments. I am also thankful to Omran Shroufi for his feedback and corrections on an earlier version of this text. Finally, I would like to thank Dr. Kevin Smets and Dr. Jan Loisen for their continuing support and invaluable counsel throughout this research. This work was supported by a PhD fellowship of the Research Foundation-Flanders (FWO): (grant number 1172019N).

\section{Conflict of Interests}

The author declares no conflict of interest.

\section{Disclaimer}

The Arab-German Young Academy of Sciences and Humanities (AGYA) is supporting the thematic issue
"Ten Years after the Arab Uprisings: Beyond Media and Liberation," edited by AGYA alumna Hanan Badr (Gulf University of Science and Technology, Kuwait) and AGYA member Lena-Maria Möller (Max Planck Institute for Comparative and International Private Law, Germany). AGYA is funded by the German Federal Ministry of Education and Research (BMBF). The authors remain solely responsible for the content and recommendations provided in this publication, which do not reflect the positions of AGYA or any of its funding partners.

\section{References}

Al-Ghazzi, O. (2017). On the afterlife of false Syria reporting. In Z. Harb (Ed.), Reporting the Middle East: The practice of news in the twenty-first century (pp. 12-32). I.B. Tauris.

Andén-Papadopoulos, K., \& Pantti, M. (2013). The media work of Syrian diaspora activists: Brokering between the protest and mainstream media. International Journal of Communication, 7, 2185-2206.

Badr, H. (2020). Egypt's media system: Historic legacies and blocked potentials for independent media. Publizistik, 65(1), 63-79. https://doi.org/10.1007/ s11616-019-00537-8

Badr, H. (2021). Before the "Arab Spring": How challengers pushed counter-issues in Egypt's hybrid media system. Media, War \& Conflict, 14(4), 522-541. https://doi.org/10.1177/1750635219894 611

Badran, Y. (2020). Strategies and (survival) tactics: The case of Syrian oppositional media in Turkey. Journal of Alternative \& Community Media, 5(1), 69-85. https://doi.org/10.1386/joacm_00075_1

Badran, Y. (in press). Independent media: Negotiating the logics of media development programs. In J. F. Khalil, G. Khiabany, T. Guaaybess, \& B. Yesil (Eds.), The handbook of media and culture in the Middle East. Wiley; IAMCR.

Badran, Y., \& De Angelis, E. (2016). “Independent" Kurdish media in Syria: Conflicting identities in the transition. Middle East Journal of Culture and Communication, 9(3), 334-351. https://doi.org/10.1163/ 18739865-00903001

Badran, Y., Loisen, J., \& Smets, K. (2021). Local associative media in Tunisia and the value of voice. The Journal of North African Studies. Advance online publication. https://doi.org/10.1080/13629387.2021. 1878888

Badran, Y., \& Smets, K. (2018). Heterogeneity in alternative media spheres: Oppositional media and the framing of sectarianism in the Syrian conflict. International Journal of Communication, 12, 4229-4247.

Badran, Y., \& Smets, K. (2021). Anatomy of a precarious newsroom: Precarity and agency in Syrian exiled journalism in Turkey. Media, Culture \& Society, 43(8), 1377-1394. https://doi.org/10.1177/ 01634437211011556 
Breiner, J. (2019, January 3). How necessity drives media innovation in Middle East, North Africa. Global Investigative Journalism Network. https://gijn.org/2019/ 01/03/how-necessity-drives-media-innovation-inmiddle-east-north-africa

Brooten, L. (2016). Burmese media in transition. International Journal of Communication, 10, 182-199.

Brownlee, B. J. (2017). Media development in Syria: The Janus-faced nature of foreign aid assistance. Third World Quarterly, 38(10), 2276-2294. https://doi.org/ 10.1080/01436597.2017.1333420

Brownlee, B. J. (2020). New media and revolution: Resistance and dissent in pre-uprising Syria. McGillQueen's University Press.

Carothers, T. (2002). The end of the transition paradigm. Journal of Democracy, 13(1), 5-21. https://doi.org/ 10.1353/jod.2002.0003

Castells, M. (2009). Communication power. Oxford University Press.

Cavatorta, F., \& Haugbølle, R. H. (2012). The end of authoritarian rule and the mythology of Tunisia under Ben Ali. Mediterranean Politics, 17(2), 179-195. https://doi.org/10.1080/13629395.2012. 694043

Chancellor, A. (2020). The women want the fall of the (gendered)regime: In what ways are Syrian women challenging state feminism through an online feminist counterpublic? Cornell International Affairs Review, 14(1), 137-183. https://doi.org/10.37513/ ciar.v14i1.561

Charaf, I. (2014, August 16-21). Alternative Syrian media: A case study, the pacific weapon against bullets. Sayedat Souria journal as example [Conference paper]. IFLA WLIC 2014, Lyon, France. http://library. ifla.org/1025

Cook, C. E. (2016a). Fragile finance: The revenue models of oppositional news outlets in repressive regimes. International Communication Gazette, 78(6), 514-535. https://doi.org/10.1177/1748048516640 212

Cook, C. E. (2016b). Money under fire: The ethics of revenue generation for oppositional news outlets. Ethical Space: The International Journal of Communication Ethics, 13(2/3), 66-80.

Couldry, N. (2009). Rethinking the politics of voice. Continuum, 23(4), 579-582. https://doi.org/10.1080/ 10304310903026594

Couldry, N. (2010). Why voice matters: Culture and politics after neoliberalism. SAGE.

De Angelis, E. (2011). The state of disarray of a networked revolution: The Syrian uprising's information environment. Sociologica, 5(3), 1-24. https://doi.org/ $10.2383 / 36423$

Dean, J. (2010). Blog theory: Feedback and capture in the circuits of drive. Polity.

Della Ratta, D. (2018). Shooting a revolution: Visual media and warfare in Syria. Pluto Press.

Della Ratta, D., Sakr, N., \& Skovgaard-Petersen, J. (2015).
Arab media moguls. I.B. Tauris.

Deuze, M., \& Witschge, T. (2020). Beyond journalism. Polity.

Dreher, T. (2009). Listening across difference: Media and multiculturalism beyond the politics of voice. Continuum, 23(4), 445-458. https://doi.org/10.1080/ 10304310903015712

El-Issawi, F., \& Benequista, N. (2020). Building regional strategies for media development in the Middle East and North Africa. Center for International Media Assistance. https://www.cima.ned.org/publication/ building-regional-strategies-for-media-developmentin-the-middle-east-and-north-africa

el-Nawawy, M., \& Khamis, S. (2013). Egyptian revolution 2.0: Political blogging, civic engagement, and citizen journalism. Palgrave Macmillan.

Enab Baladi. (n.d.). Housing, land, and property. https://www.enabbaladi.net/archives/category/ rights-freedoms/hlp-rights

Hafez, K. (2015). Radically polarized publics and the demise of media freedom in Egypt. Égypte/Monde Arabe, 12, 37-49. https://doi.org/10.4000/ema. 3397

Hassanpour, A., Sheyholislami, J., \& Skutnabb-Kangas, T. (2012). Introduction. Kurdish: Linguicide, resistance, and hope. International Journal of the Sociology of Language, 2012(217), 1-18. https://doi.org/ 10.1515/ijsl-2012-0047

Hirschman, A. O. (1970). Exit, voice, and loyalty: Responses to decline in firms, organizations, and states. Harvard University Press.

How do we continue? How do we make an impact? (2019, May 4). Mada Masr. https://www.madamasr. com/en/2019/05/04/feature/society/how-do-wecontinue-how-do-we-make-an-impact

Howard, P. N., \& Hussain, M. M. (2013). Democracy's fourth wave? Digital media and the Arab Spring. Oxford University Press.

Issa, A. (2016). Syria's new media landscape: Independent media born out of war (MEI Policy Paper No. 2016-9). The Middle East Institute. https://www. mei.edu/content/syria-s-new-media-landscape

Jarrar, S. (2018, January 15). Will Jordan reclaim its territory from "Israel" in the next year? 7iber. https://www.7iber.com/politics-economics/wellget-them-back-will-jordan-reclaim-its-territory-inthe-next-year

Manyozo, L. (2016). The language and voice of the oppressed. In O. Hemer \& T. Tufte (Eds.), Voice \& matter: Communication, development, and the cultural return (pp. 43-58). Nordicom, University of Gothenburg.

Matar, D., \& Helmi, K. (2020). Liminality, gendering, and Syrian alternative media spaces. In S. Maltby, B. O'Loughlin, K. Parry, \& L. Roselle (Eds.), Spaces of war, war of spaces (pp. 143-158). Bloomsbury Academic.

Mezghanni, S. S. (2014). Reinforcing citizenship through civil society and media partnerships: The case of com- 
munity radios. The Journal of North African Studies, 19(5), 679-693. https://doi.org/10.1080/13629387. 2014.975665

Myers, M. (2018). Nigerian newspapers: The attractions and drawbacks of foreign aid funding. African Journalism Studies, 39(2), 30-41. https://doi.org/ $10.1080 / 23743670.2018 .1473273$

Norris, P. (2008). The role of the free press in promoting democratization, good governance, and human development. In M. Harvey (Ed.), Media matters: Perspectives on advancing governance \& development from the Global Forum for Media Development ( $\mathrm{pp}$. 66-75). Internews Europe.

Noske-Turner, J. (2014). Evaluating the impacts of media assistance: Problems and principles. Global Media Journal-German Edition, 4(2). http://globalmedia journal.de/en/2015/01/16/evaluating-the-impactsof-media-assistance-problems-and-principles

Radsch, C. C. (2008, September 29). Core to commonplace: The evolution of Egypt's blogosphere. Arab Media \& Society. https://www.arabmediasociety. com/core-to-commonplace-the-evolution-ofegypts-blogosphere

Russell, A. (2016). Journalism as activism: Recoding media power. Polity.

Ryan, C. R. (2018). Jordan and the Arab uprisings: Regime survival and politics beyond the state. Columbia University Press.

Sakr, N. (2016). Survival or sustainability? Contributions of innovatively managed news ventures to the future of Egyptian journalism. Journal of Media Business Studies, 13(1), 45-59. https://doi.org/10.1080/ 16522354.2015 .1125608

Salama, V. (2012). Covering Syria. The International Journal of Press/Politics, 17(4), 516-526. https://doi.org/ $10.1177 / 1940161212456774$

Saleh, F. (2020, September 29). Queerness and the revolution: Towards an alternative Syrian archive. SyriaUntold. https://syriauntold.com/2020/09/29/ queerness-and-the-revolution-towards-analternative-syrian-archive

Sarkisjan, S. (2021, January 29). Ethical charter for Syrian media approves complaints mechanism. Free Press Unlimited. https://www.freepressunlimited.org/ en/current/ethical-charter-syrian-media-approvescomplaints-mechanism

Sbouai, S. (2015, May 17). LGBT: Le coup de pouce du Net [LGBT: The helping hand of the internet]. Inkyfada. https://inkyfada.com/fr/2015/05/17/lgbtle-coup-de-pouce-du-net-tunisie

Schmoll, K. (2021). Listening as a citizenship practice post-Arab Spring: Mediated civic listening as a struggle, duty, and joy in urban Morocco. Media, Culture \& Society, 43(1), 84-100. https://doi.org/10.1177/ 0163443720939455

Shirky, C. (2009). Here comes everybody: How change happens when people come together. Penguin.

Tatomir, B., De Angelis, E., \& Sadouskaya-Komlach, M.
(2020). Syrian independent exile media. International Media Support. https://www.mediasupport. org/publication/syrian-independent-exile-media

Teti, A., \& Gervasio, G. (2021). No bread, no freedom, no social justice: How EU-Egyptian human rights discourse undermines democracy. In A. Salvatore, S. Hanafi, \& K. Obuse (Eds.), The Oxford handbook of the sociology of the Middle East. Oxford University Press. https://doi.org/10.1093/oxfordhb/ 9780190087470.013 .44

Waisbord, S. (2019). The vulnerabilities of journalism. Journalism, 20(1), 210-213. https://doi.org/ $10.1177 / 1464884918809283$

Waisbord, S., \& Jones, A. (2010, September 2-5). International media assistance and aid effectiveness: Conceptual blindspots and institutional incentives [Conference paper]. American Political Science Association 2010 Annual Meeting, Washington, DC, US. https://papers.ssrn.com/abstract $=1642218$

Wall, M., \& el Zahed, S. (2015). Syrian citizen journalism: A pop-up news ecology in an authoritarian space. Digital Journalism, 3(5), 720-736. https://doi.org/ 10.1080/21670811.2014.931722

Watts, E. (2001). "Voice" and "voicelessness" in rhetorical studies. Quarterly Journal of Speech, 87(2), 179-196. https://doi.org/10.1080/0033563010938 4328

Wedeen, L. (1999). Ambiguities of domination: Politics, rhetoric, and symbols in contemporary Syria. University of Chicago Press.

Wedeen, L. (2019). Authoritarian apprehensions: Ideology, judgment, and mourning in Syria. University of Chicago Press.

Wessels, J. I. (2017). Video activists from Aleppo and Raqqa as "modern-day Kinoks"? An audiovisual narrative of the Syrian revolution. Middle East Journal of Culture and Communication, 10(2/3), 159-174. https://doi.org/10.1163/18739865-01002005

What we know about the Israeli gas deal. (2016, September 29). 7iber. https://www.7iber.com/politicseconomics/what-we-know-about-the-israeli-gasdeal

Wollenberg, A., \& Pack, J. (2013). Rebels with a pen: Observations on the newly emerging media landscape in Libya. The Journal of North African Studies, 18(2), 191-210. https://doi.org/10.1080/13629387. 2013.767197

Wollenberg, A., \& Richter, C. (2020). Political parallelism in transitional media systems: The case of Libya. International Journal of Communication, 14, 1173-1193.

York, J. (2012). The Arab digital vanguard: How a decade of blogging contributed to a year of revolution. Georgetown Journal of International Affairs, 13(1), 33-42.

Youssef, D., \& De Angelis, E. (2021, April 2). "Palmyra syndrome": What are Syrians allowed to speak about amid war and revolution? SyriaUntold. https:// syriauntold.com/2021/04/02/palmyra-syndrome- 
what-are-syrians-allowed-to-speak-about-amid-warand-revolution

Zaki, H. A. (2021, January 21). How Egyptian women have broken the stigma around sexual violence. Mada Masr. https://www.madamasr.com/en/2021/ 01/21/opinion/u/how-egyptian-women-havebroken-the-stigma-around-sexual-violence

Zelizer, B. (2015). Terms of choice: Uncertainty, journalism, and crisis. Journal of Communication, 65(5), 888-908. https://doi.org/10.1111/jcom.12157

\section{About the Author}

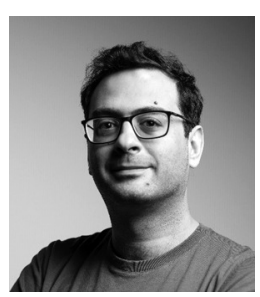

Yazan Badran (PhD) is visiting professor at the Department of Communication Sciences and postdoctoral researcher at the Echo and imec-SMIT research centres at the Vrije Universiteit Brussel, Belgium. He was a PhD fellow of the Research Foundation-Flanders (FWO) and obtained a PhD in media and communication studies from the Vrije Universiteit Brussel in 2021. His research interests lie at the intersection of new journalism and political activism in the post-2011 Middle East and North Africa region (MENA) and the political economy and journalistic practices of emerging media organisations, particularly in Syria and Tunisia. 